\title{
The Drawing of an Opera Theatre for Boito's Competition (1939)
}

\author{
Alessandra Capanna \\ Paola Magnaghi-Delfino \\ Giampiero Mele \\ Tullia Norando
}

Abstract

In 1938/39, the Accademia delle Belle Arti di Brera published the competition Camillo Boito entitled Project for a theatre to be used for performances of lyrical art.

A group of students, G. Belloni, A. Fiocchi, A. Magnaghi-Delfino, M. Terzaghi, from the Regio Politecnico di Milano attended to the contest and won the first prize. The design of the theatre, which was meant to arise on a free area in a public garden, with a seating capacity of 3000, plus 200 on the stages, had as its motto Tremila 3000. All seats, as often happens in Italian theatres, had to be in conditions of visibility as uniform as possible.

Bibliographic sources are limited to a single article published on Costruzioni Casabella signed by Giuseppe Pagano.

The documentary and iconographic sources were found in the Historical Archive of the Accademia delle Belle Arti di Brera and at the CASVA (Centre for Advanced Studies on Visual Arts) in Milan.

This work analyses the drawings for the identification of the basic module and the rational schemes used by the creators for the definition of the project presented in the competition.

The research shows a rational use of the square module, learned during the years of apprenticeship at Terragni's Como studio, which will be the common denominator in most of the projects that will be carried out by the Magnaghi-Terzaghi studio, in particular in the Casa dei Nidi (House of the Nests) (1939) and in the BICA building (1955).

Keywords

drawing, project, theatre, geometry, square matrix.

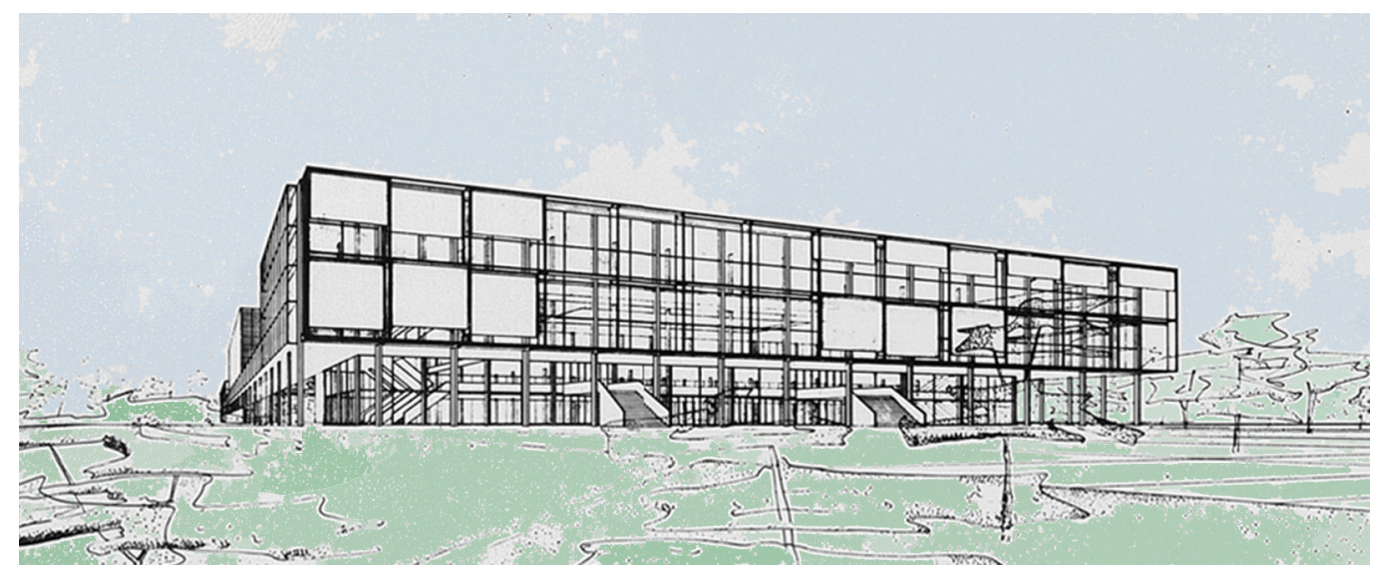




\section{Introducing Augusto Magnaghi-Delfino and Mario Terzaghi}

In 1939, the Milan Politecnico architecture students A. Magnaghi and M. Terzaghi with G. Belloni, and A. Fiocchi took part in the Camillo Boito's competition that had as subject Project for a theatre to be used for opera performances, identified with the motto Tremila3000.

Still students, Magnaghi and Terzaghi attended Terragni and Lingeri's studio and in 1939 they built the Casa dei nidi (House of the nests) in Fino Mornasco (CO), a residential building with rationalist lines and they won, with Lingeri and Cattaneo, a competition for the Palace of Trade Unions in Como. In 194I they participated in the primordial Futurist Group Sant'Elia.

From 1948 to 1952, Magnaghi worked for SAFFA. In this period he designed the first fitted modular kitchen for which, on 1954, he won the Compasso d'Oro prize.

The two architects dedicated their working activity to public housing, schools, hospitals and product design for the famous Olivari Company. In 1947, they studied the application of prefabricated construction systems in some buildings in the QT8 district in Milan. In 1950, they realized the Vita \& MayerVillage for Workers in Cairate (VA).

From 195I to 1955, they designed numerous complexes for the INA-CASA, in Gemonio (VA), in Magenta (MI) and in Monza (MB).

In 1955, they designed the Bica-Montecatini office building in Via San Giovanni sul Muro in Milan.

After the realization of the elementary school in Jerago (VA), they designed buildings for the Feltre district and Comasina (Milan) and the INAM clinics of Laveno, Cremona and Milan. They collaborated with Ignazio Gardella at the project of the Ivrea Hospital and with Vittorio Gandolfi for the project of the new airport in Lagos (Nigeria, 1962). In 1959, they built the house in via Caboto where Augusto Magnaghi lived until 1963 when, undermined by a serious illness, he passed away.

In the present report of research, we want to illustrate the method that Magnaghi and Terzaghi adopted to outline the project of the Theatre Tremila 3000, starting from the square grid. It is a process of rationalization of the measure, used by the two architects in the construction of the shape of other important projects such as the building for the BICA Company (1955-58). This office building can be included in the Rationalist language because the adopted design method is highly attributable to that of the house in Fino Fig. I. Ground floor plan
and Perspective views of the headquarters of the Fascist Union of Industria Workers ULI in Como. (Archivio C.A.S.V.A Milano).

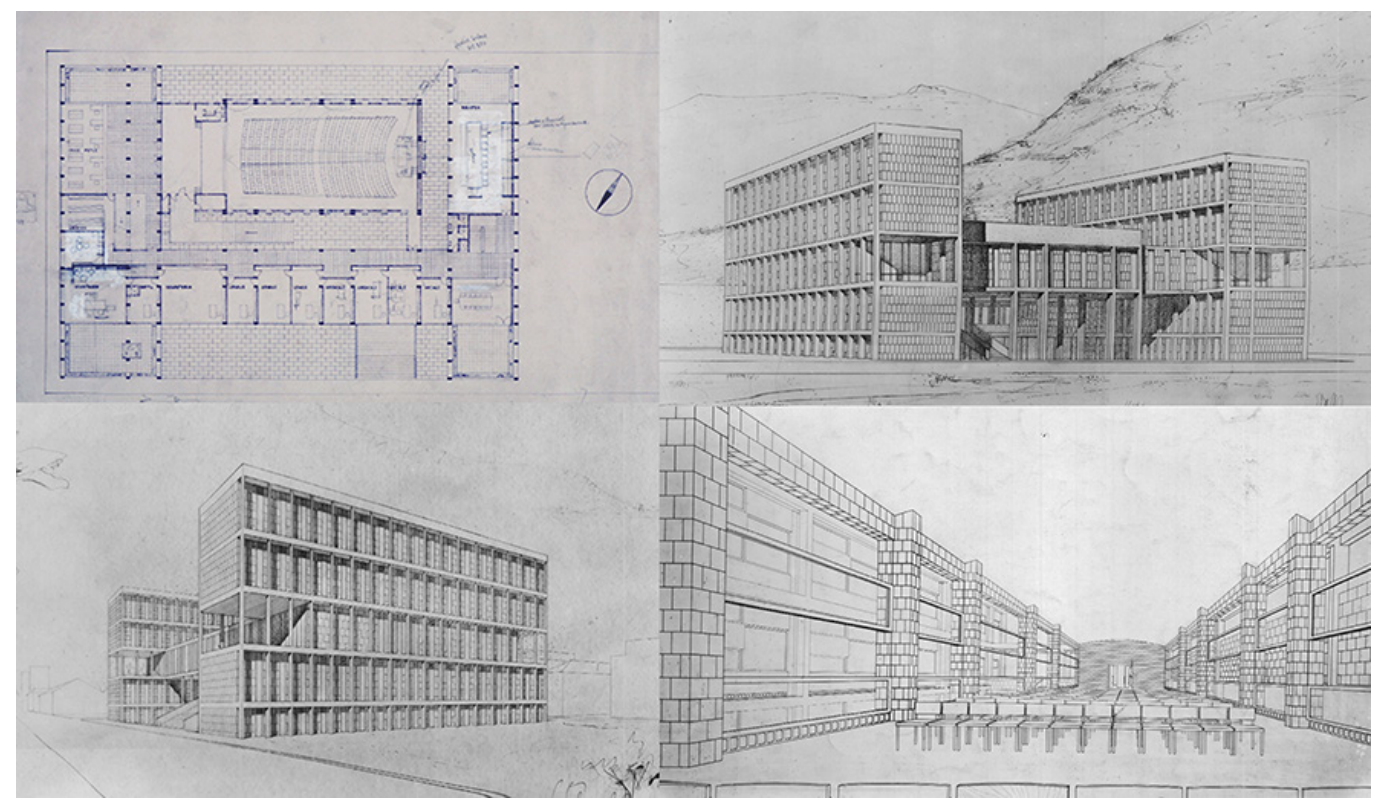


Mornasco (CO) that they planned when they were still students and collaborated with the masters of Italian Rationalism: Pietro Lingeri, Cesare Cattaneo and Luigi Origoni. With them, between 1940 and 1943, they built the building for the headquarters of the Fascist Union of Industrial Workers - ULI in Como (fig. I). Projects, as well as awards obtained since 1936, are evidence that even at that time Magnaghi and Terzaghi learned this method from the rationalist architects [Feraboli 2006].

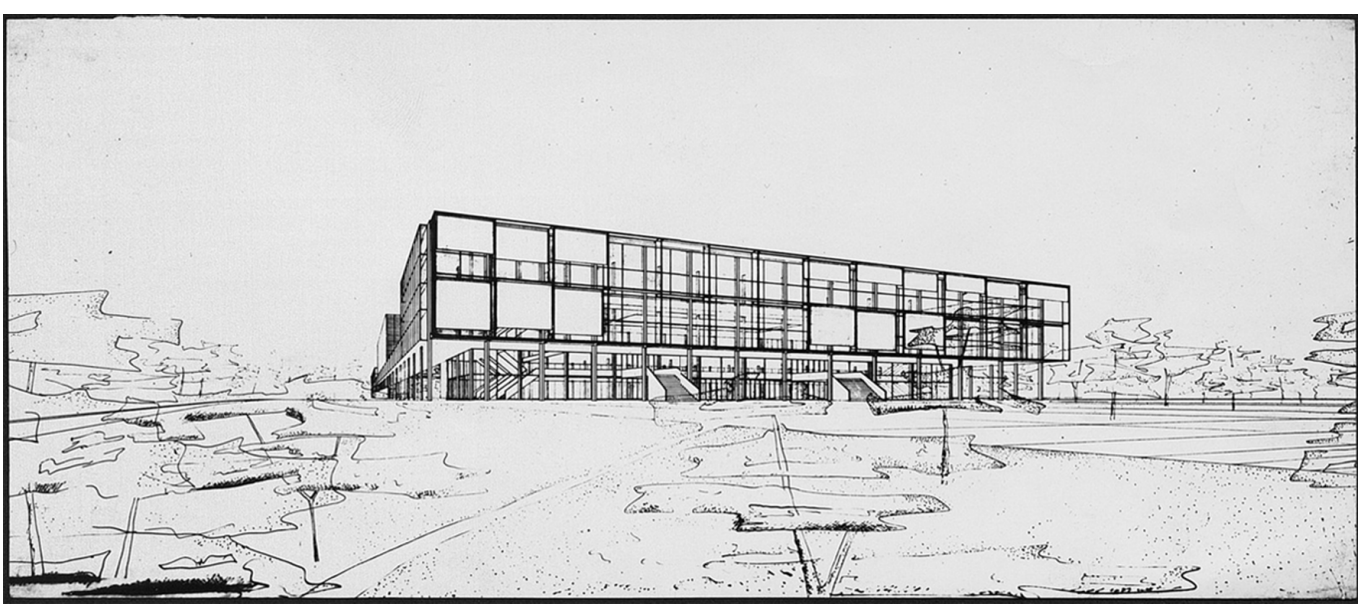

\section{From the Drawings, the Description of the Project for the Theatre Tremila3000}

Camillo Boito, brother of the musician Arrigo, graduated in architecture at the Venice Academy. From 1860 to 1908, he taught architecture at the Accademia of Belle Arti in Milan and then, for 43 years, he was professor at the Istituto Tecnico Superiore in Milan, later Politecnico di Milano.

To honour Camillo, the Accademia di Brera instituted an award named Camillo Boito, financed with I/3 of the proceeds of the work Mephistopheles, composed by his brother Arrigo. In 1939, G. Belloni, A. Fiocchi, A. Magnaghi-Delfino, M. Terzaghi took part in the competition that had as subject Project for a theatre to be used for opera performances. They participated in the competition with the motto Tremila3000 and won the first prize that consisted of 15,000 lire.

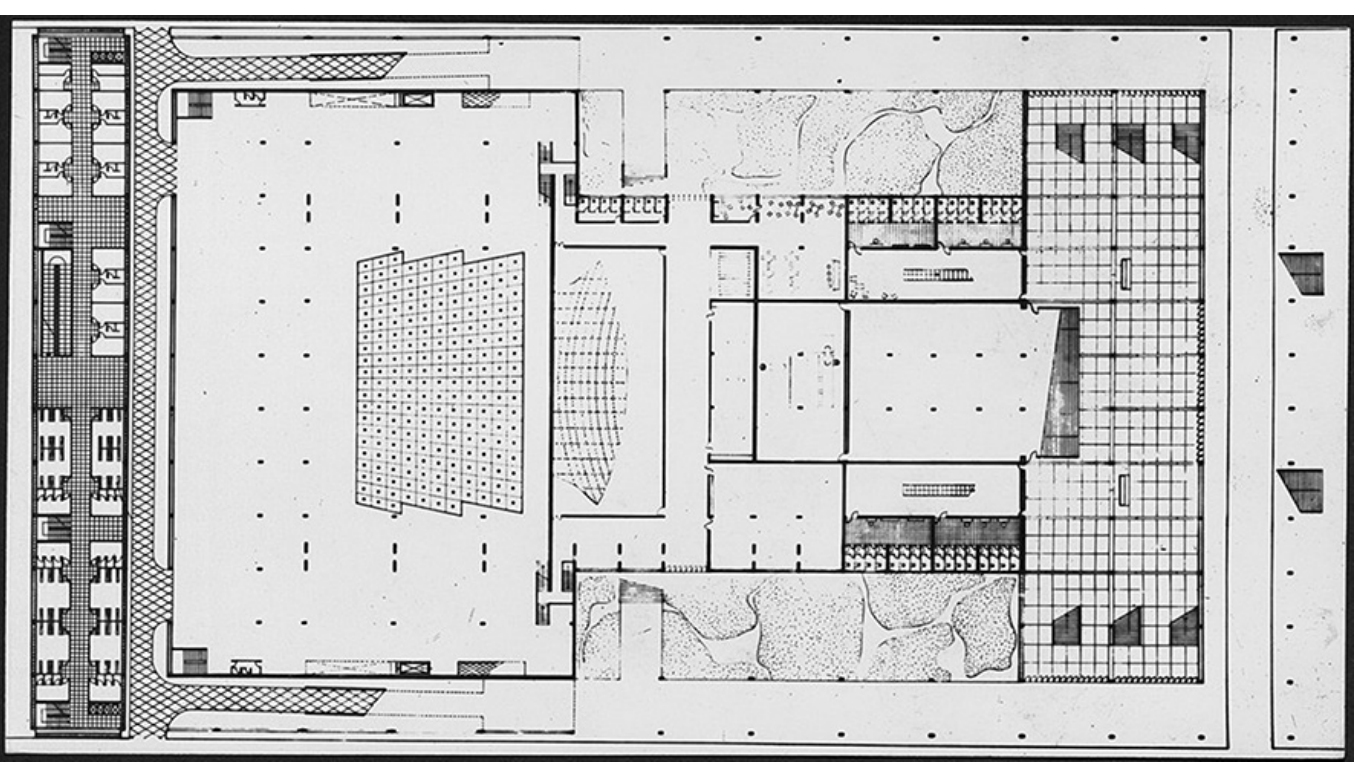


Giuseppe Pagano, including the theatre in the idea of the 1930s great projects left on paper, described and commented it as follows: "This study brings not only an intelligent contribution to the particularly difficult solution of the great opera house, but above all, for that fresh and conscious stylistic coherence that comes alive with the liveliness of an intelligence and the weight of rigorous aesthetic control the whole project and merges it into a concise elementary evident sense of unity" [Pagano 1942, p. 2].

The students imagined the project for the theatre in a public park, arranged with the main facade facing the street that connects it to the main road. In front of it, there is a large green pedestrian area leading to the accesses, separated from car traffic (fig. 2).

The spectators' atrium of the theatre, accessible by two external stairs, is $3 \mathrm{~m}$ higher respect to the street level, while the driveways are on the lower level. The whole building is included in a rectangular perimeter. Other rectangular shapes containing the atria, the stairs and the foyer on the one hand, and the stage and services inherent in the scenic mechanisms, on the other hand, are organized orthogonally respect to the hall. The administrative offices, the library, the archives, the emergency room, are placed on two lateral elements at a higher level, $6 \mathrm{~m}$ above the main hall, and are spaces of connection between the atria and the stage. These two porches, following the different height of the interiors,

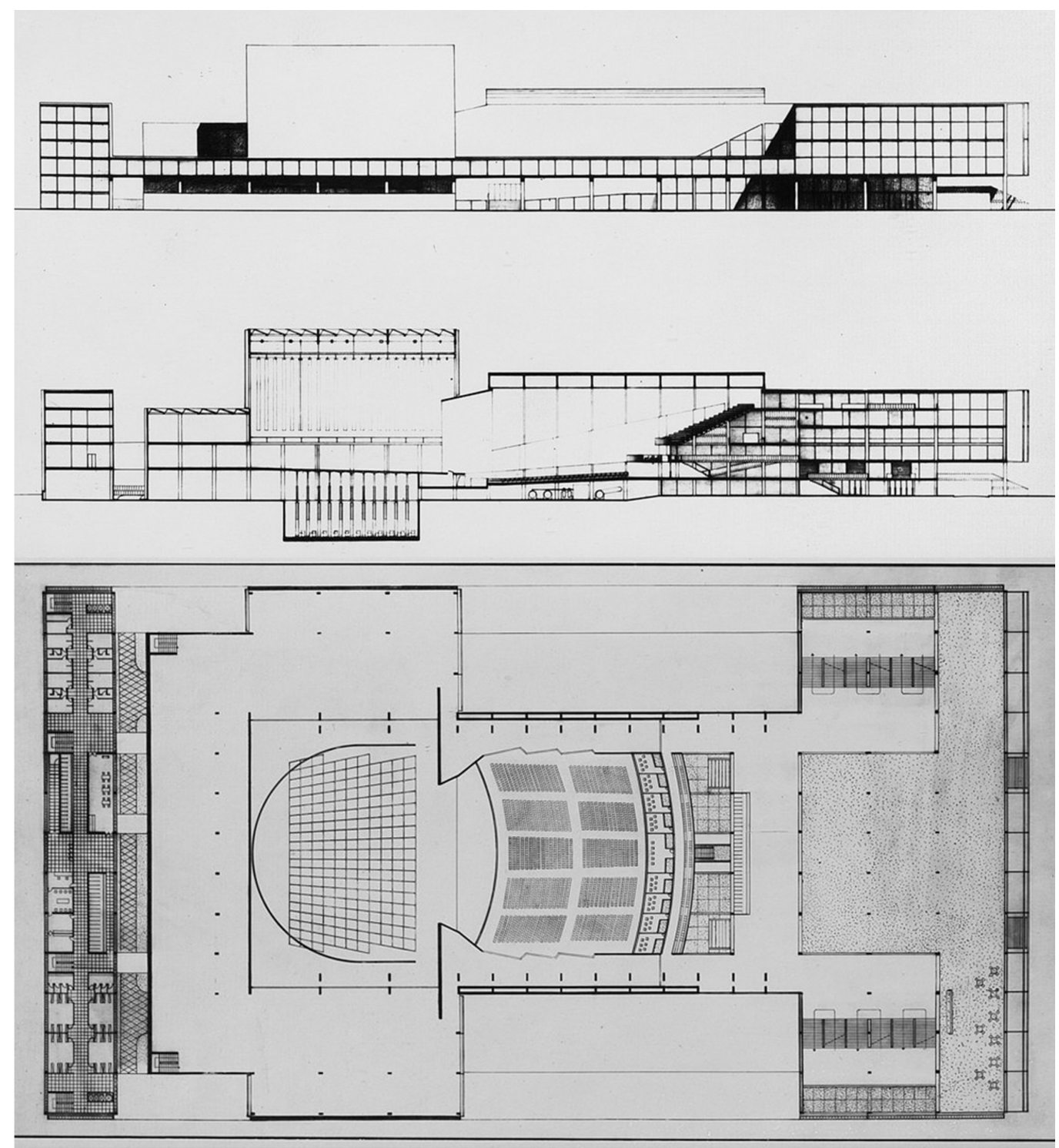


allow covered exit, on one side for public services, and on the other, to the hallway for parking spaces (fig. 3).

The rectangular shape has been adopted for the plan of the theatre, because it works better both in terms of visibility and in terms of aesthetics. The acoustic question was settled with a number of inclined lateral panels, situated $3 \mathrm{~m}$ above the level of the floor. The volume of the theatre is around $20,000 \mathrm{~m}^{3}$, given that acoustic requirements recommend theatre volumes not exceeding $25,000 \mathrm{~m}^{3}$ (fig. 4).

The trapezoidal or fan-shaped theatre has many advantages respect to the other forms, because it eliminates echoes and multiple reflections and, thanks to divergent walls with respect to the axis of the room, it contributes to redirect the sound strengthening its intensity.

Summarizing the list of the principal acoustic requirements: absence of echo phenomena; limitation of multiple reflection; preservation of the characteristic qualities of sound waves to ensure each listener the clear perception of sounds. At the same time, visibility is perfect when a complete view of the scene is possible from all points of the room, but of course, the visibility condition gradually deteriorates as the distance from the scene grows along

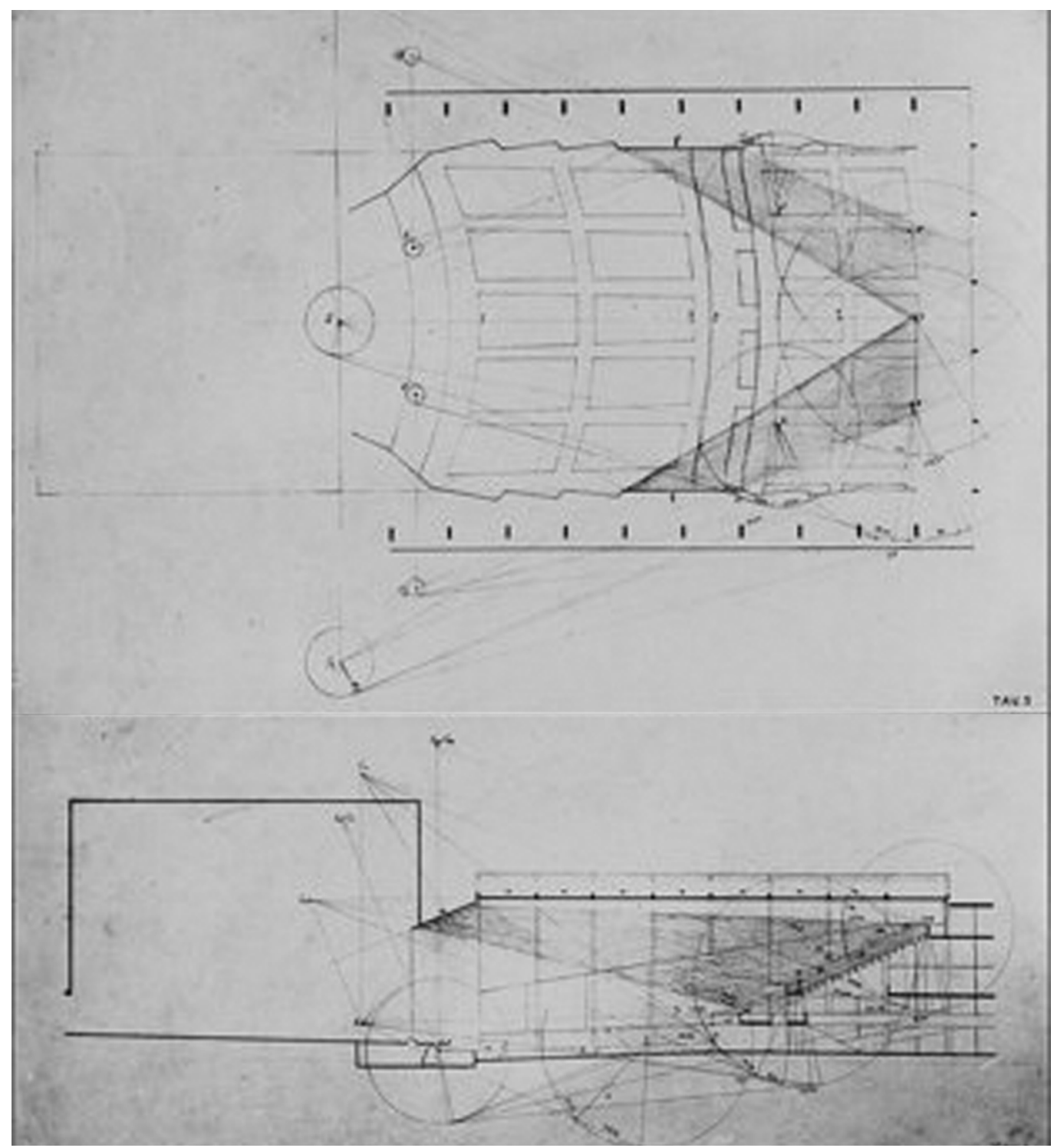


the longitudinal axis. The hall should therefore have a rectangular shape a little wider than that of the scene. These two requirements are best optimized in an intermediate-sized room, with a maximum capacity of 3000-4000 seats. For this project, the four young students in architecture have therefore thought of a room shape that, to maintain perfect visibility, retains the advantages of the fan-shaped room, inside a rectangular plan with special reflective panels variously arranged along the inclined side-walls.

The purpose of this setting of acoustic panels, in addition to reflect the sounds on the listeners, is to direct the sound waves towards the areas furthest from the source, so as to increase, in proportion to the distance, the number of reflected rays obtaining intensity distribution as uniform as possible throughout the room (fig. 5).

In the drawings, that we examine, the acoustic conditions of the room, the sound sources, which take infinite positions, given the mobility of the singers and the vastness of the orchestra pit, have been reduced for simplicity to three. However, the function of the reflective zones remains unchanged for any number of sources considered. The walls near the proscenium have the task of reflecting and strengthening the voices of the singers as well as the sounds produced by the orchestra.
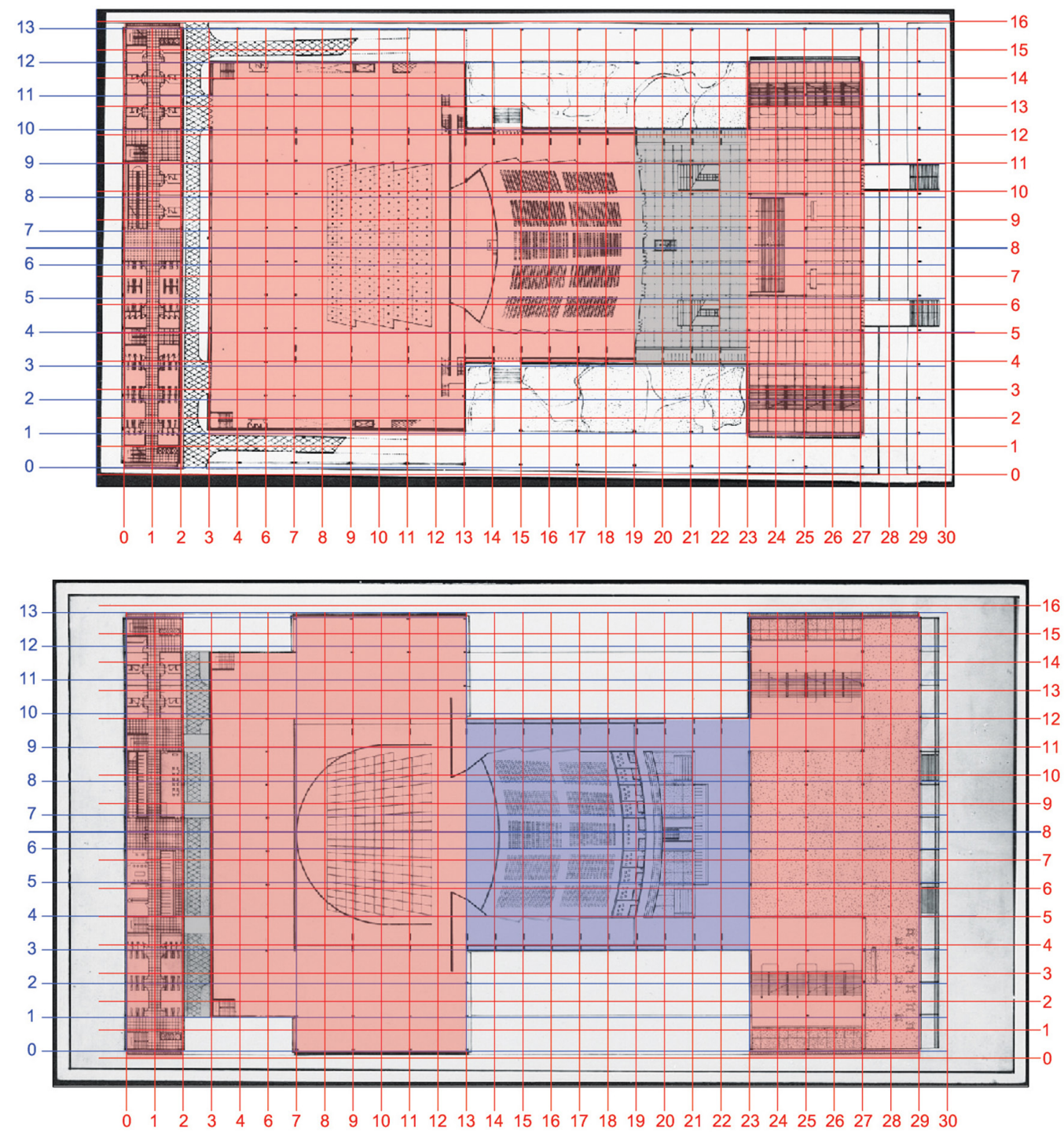
The shape of the ceiling is fundamental for the acoustic study of the room, for which it was assumed to maintain the minimum height allowed by the size of the stage. Given the continuity of the room and the mobility of the singer, the solution of the flat ceiling was imposed (fig. 5).

A short ramp of stairs leads from the cloakroom atrium to the hallway of the stages, which had to contain no more than 200 spectators. The layout of the seats was also the best in the acoustic investigation for the perfect fusion of sounds. On the stage level, $3 \mathrm{~m}$ above the auditorium, there is the foyer, which is accessed via two short ramps.

The floor of the stage is divided into 200 platforms of $4 \mathrm{~m}^{2}$ each, with independent hydraulic machines, controlled by a central panel. The division of these platforms follows the central scenic perspective so that any scenic construction in height or depth can be performed by raising or lowering the platforms.

This system for the convenience of preparing the scenes retains the advantages of the revolving stage, which would have required a depth twice that of $36 \mathrm{~m}$. of the present project. The 200 orchestra components have separate lateral entrances.

\section{The Analysis of the Drawings in Magnaghi-Terzaghi Projects}

The geometric analysis of the designs of the Tremila3000 theatre was an opportunity to investigate the use of the square module in the design process of the Magnaghi-Terzaghi studio. This modulation system, which has in the square the generating motif of the form, shows a solid compositional method learned in the years of university.

In addition to the geometric analysis of the drawings of the Tremila300 Theatre, we have analyzed the Nest House (1939) drawings in and those of the BICA office building (1955).
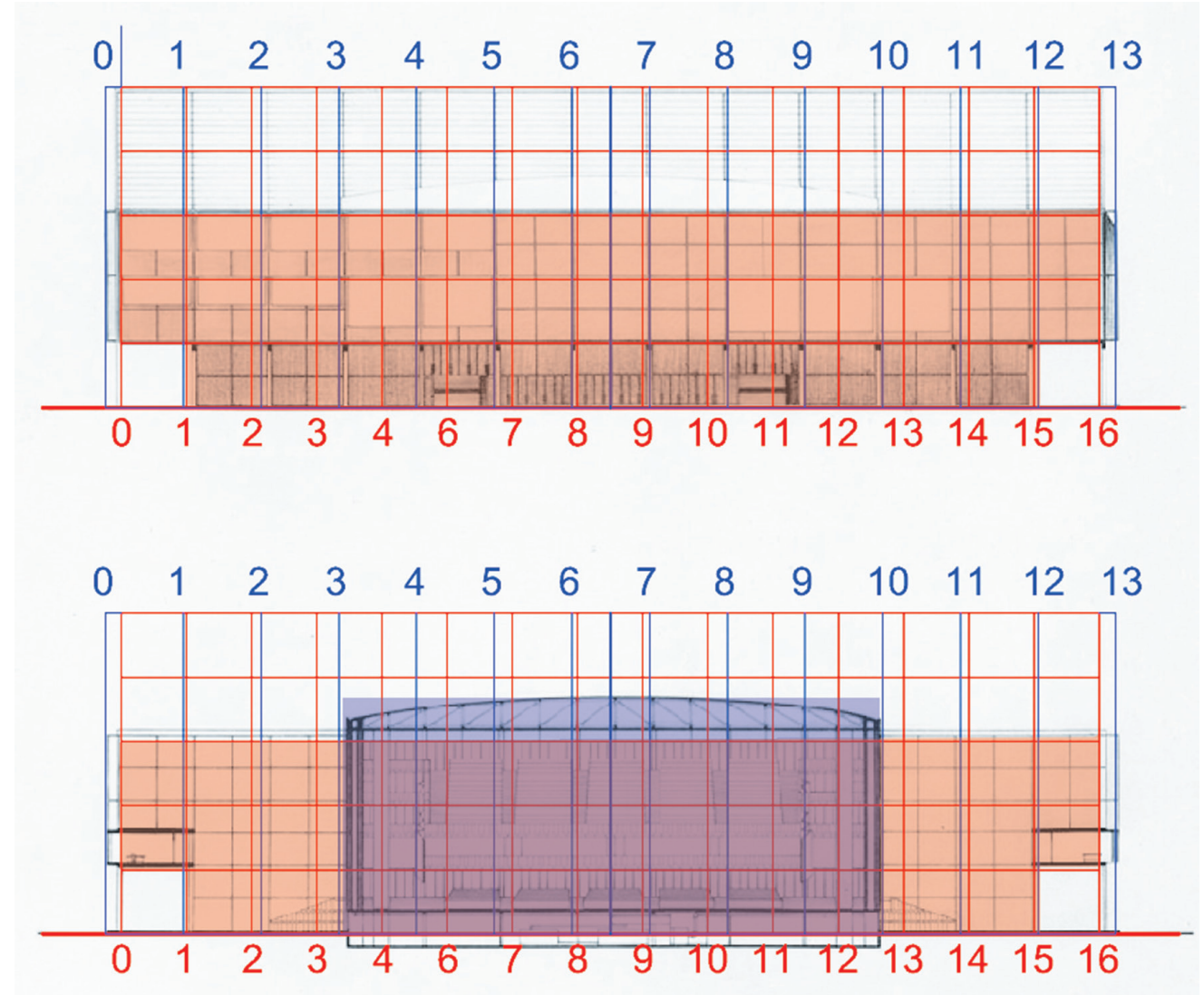
Fig. 8. Grid and geometric schemes for the definition of Casa dei Nidi (graphic elaboration by the authors)
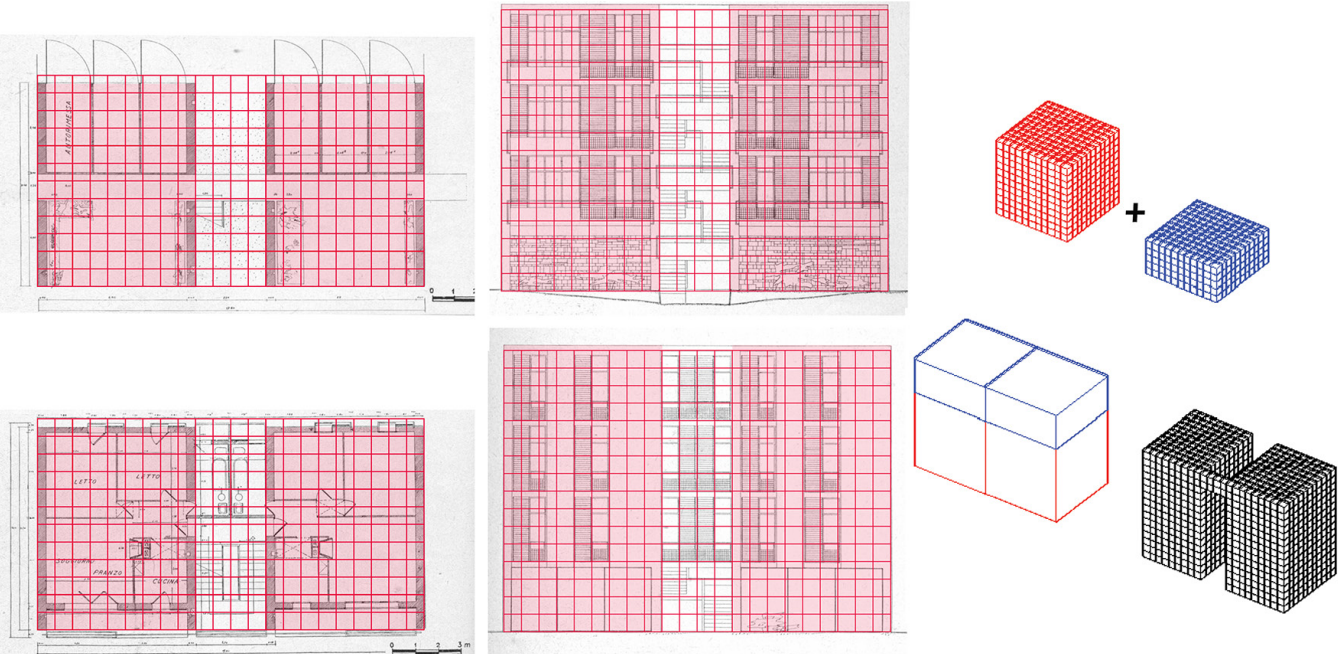

The square grid of the Theatre Tremila3000 is obtained considering a rectangle of a 29:16 proportion. The measurement of the side of the module is $6 \mathrm{~m}$. The short side of the 16-module rectangle is divided into 13 (fig. 6).

The elevations are modulated on a grid that is half that of the plan. The side elevation shows a square grid made up of $58(29 \times 2)$ modules in length and $6(3 \times 2)$ modules in height. The main elevation shows a grid that has the height of the measurement of the grid of the side elevation in width. The measurement of the module is obtained by dividing 32 modules in height by 26 parts, thus obtaining a rectangular grid that is not very visible. This identifies a main elevation which has an aspect ratio of 26:9 (13:3), (fig. 7).

In the Casa dei Nidi (1939) we identified the geometric matrices on which the architects based the project. The $0.80 \mathrm{~m}$-sided square is the module that they used to design this architecture. The plan is incorporated into a double square made by II,5 $\times 22$ modules and the elevation is $22 \times 16$ modules. The $0.80 \mathrm{~m}$ module has an obvious convenience for the control of the facade because the distance from the story of the floor below to the floor above is $3.20 \mathrm{~m}$, equal to 4 modules.

The control of the project is given both by the tessellation of the plan with squares and of the space with cubes of side equal to $0.80 \mathrm{~m}$. The general measures of the plan are 9.20 $\times 17.60=161.92$ square meters $(11.5 \times 22=253$ modules $)$. The total volume of the building, all inclusive (calculated empty to full) is $161.92 \times 12.80=2072.576 \mathrm{~m}^{3}(253 \times 16=$ 4048 modules), (fig. 8). The gross surface area of 6 apartments from the first to the third floor is $66,24 \mathrm{~m}(9 \times 11.5=103.5$ modules $)$. A semi-open staircase connecting the different levels of the building is placed in a space of $6.5 \times 4=26$ modules equal to $3.20 \times 5.20$ $=16.64 \mathrm{~m}^{2}$. The openings on the main façade are equal to 3 modules with sliding shutters fitting exactly in the filled part of the wall. The ground floor originally had two single-span porches on the front side of building, in plan composed of $9 \times 6.5$ modules $(7.20 \times 5.20=$ $\left.37.44 \mathrm{~m}^{2}\right)$, which almost immediately have been closed to obtain two additional housing units [Capanna, Mele 2018].

Also, in the Bica-Montecatini office building, the two architects chose the square as a basic module by adopting a 3,34 × 3,34 m. grid that generates the shape in plan and scans the rhythm of the facade. The plan is set on a 5:14 ratio grid and the main elevation is a rectangle (fig. 9).

The structure of the main facade presents a protrusion of $0.3 \mathrm{~m}$ wide that emphasizes the verticality of the building and of the grid. The measurement of the span rating of the pillars is the same as the side of the module chosen to draw the building $(3.34 \mathrm{~m})$. The number of pillars is not equal to the number of modules: they are 13 instead of 15 because of the presence of the span without pillars under which the road passes through. The measured 
drawing of the façade has wisely incorporated this reduction. Indeed, $3.34 \times 14$ would give a total length of $46.76 \mathrm{~m}$, but due to the lack of the two pillars the real length of the façade is $46.16 \mathrm{~m},(2 \times 0.3=0.60 ; 46.76-0,60=46.16 \mathrm{~m})$. The size of the aluminum window-frames that characterize the façade is a consequence of the choice of the module and the dimension of the pillars. The size of the window frames, equal to I,033 m, derives from the subdivision of the measure of the module minus that of the pillar $(3.34-0.30=3.04 \mathrm{~m}$, $3.04 / 3=1.033)$. Therefore, the window frame has a ratio of $1: 3$. As previously mentioned, the size of the window and the lack of two pillars causes a reduction in the overall length of the project. This length has been cleverly rationalized, in fact, its calculation is simple when it is known the structure of the matrix that generated the project. If we consider, in fact, the number of spaces between the pillars (I I) and the measure of the span (3.34 m), the total length is $3.34 \times 1 \mathrm{I}=36.74$. To this measure must be added the span of 9.42 and the width of a pillar $0.30 \mathrm{~m}$. The result is equal to $46.46 \mathrm{~m}$.

\section{Conclusions}

The square grid is the tool used by Magnaghi and Terzaghi to generate an innovative architecture and it is perfectly in line with their times. In fact, the aesthetic rhythm of this architecture is based on a geometric grid that generates pure forms. This grid is referred to the classic ad quadratum background, so deep-rooted in the Italian tradition to constitute the basis of the new Italian Rationalist Architecture as theorized by the Gruppo 7.

The modern architecture created by the two architects is strongly mathematical in its conception.

The square and the rectangle at the base of their architectures show a rationality that binds number, shape and size, generating a modern form that bases its rationalist roots in the classical tradition of the history of Architecture of the past.

In conclusion, the tools and rational methodology described are at the basis of the architectural composition and in particular in Magnaghi and Terzaghi's design method. They handled a logical deductive approach with practical purposes that in geometry found an important tool to generate the architectural form.
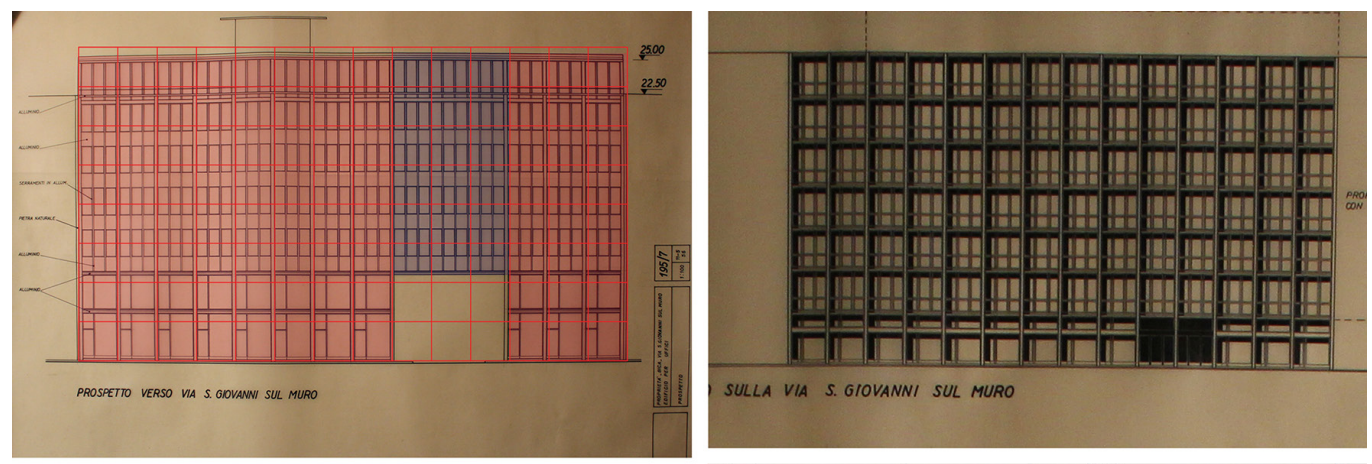

Fig. 9. Square grids useful for defining the shape of the BICA Montecatini office building (graphic elaboration by the authors).
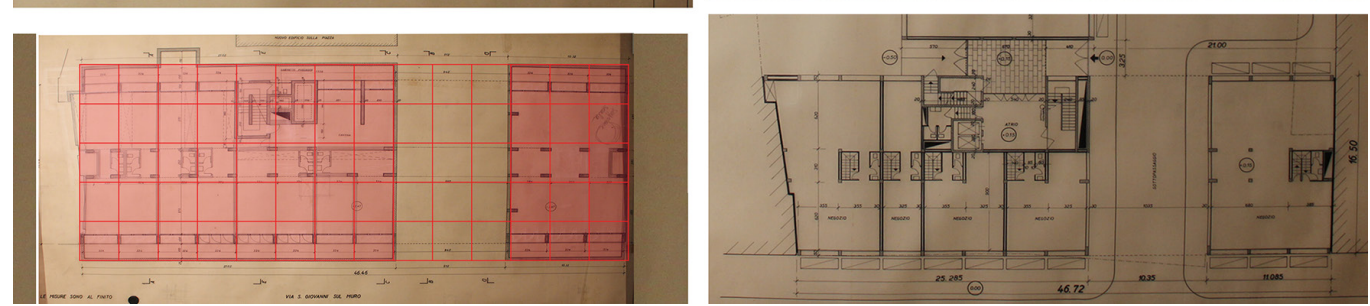


\section{References}

Capanna Alessandra, Mele Giampiero (20 I8). Square and triangular matrices in Magnaghi-Terzaghi's architectures. In Szarkova Dagmar, Letavaj Peter, Richtarikova Daniela et al. (eds.). I Th conference in applied mathematics Aplimat 2018 proceedings. Bratislava, 6-8 February 20 8. Red Hook, NY: Curran Associates, Inc., pp. 744-755.

Feraboli Maria Teresa (2006). Archivio dell'architetto Terzaghi. Milano: Milano: Comune di Milano, pp. 70-75.

Pagano Giuseppe (1940). Casa a Fino Mornasco. In Casabella, n. I50, giugno 1940, pp. 20-27.

Pagano Giuseppe (1942). Progetto di teatro lirico per 3000 posti. In Costruzioni Casabella, n. I73, Maggio 1942 , pp. 2-7.

\section{Authors}

Alessandra Capanna, Sapienza Università di Roma, alessandra.capanna@uniromal.it

Paola Magnaghi-Delfino, Politecnico di Milano, paola.magnaghi@polimi.it

Giampiero Mele, Università degli Studi eCampus, giampiero.mele@uniecampus.it

Tullia Norando, Politecnico di Milano, tullia.norando@polimi.it

To cite this chapter: Capanna Alessandra, Mele Giampiero, Magnaghi-Delfino Paola, Norando Tullia (2020). The drawing of an Opera Theatre for Boito's competition (1939). In Arena A., Arena M., Brandolino R.G., Colistra D., Ginex G., Mediati D., Nucifora S., Raffa P. (a cura di). Connettere. Un disegno per annodare e tessere. Atti del $42^{\circ}$ Convegno Internazionale dei Docenti delle Discipline della Rappresentazione/Connecting. Drawing for weaving relationships. Proceedings of the 42th International Conference of Representation Disciplines Teachers. Milano: FrancoAngeli, pp. I035- I044. 